\title{
Modelos experimentais de formação de cadeias de montanhas no contexto dos Ciclos de Wilson
}

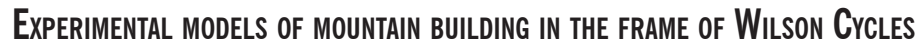

\section{EDITE BOLACHA}

IDL- Instituto Dom Luiz, Faculdade de Ciências da Universidade de Lisboa (FCUL), Campo Grande, Lisboa, Portugal. e-mail:epbolacha@fc.ul.pt

\section{Manuscrito: \\ Recebido: 06/09/2014 \\ Corrigido: 06/04/2015 \\ Aceito: 05/05/2015}

Citation:Bolacha E. Modelos experimentais de formação de cadeias de montanhas no contexto dos ciclos de Wilson. Terræ Didatica, 11(3):127-137. < http://www.ige.unicamp.br/ terraedidatica/ $>$.

Keywords: Analogue modeling, Wilson Cycle, mountain building, Plate Tectonics, formal and non formal learning.

\begin{abstract}
This paper suggests some experiences of analog modeling to simulate the formation of mountain ranges in the context of the Wilson cycle. However, not only the continental collision, or the final phases of the cycle, are shown, as is common, but also the previous ones, related to subduction, which can explain many cases. The relevance of this approach stems from data obtained in investigations in which these experiments were applied in the classroom and in a science museum. They revealed that subduction models allow students to better conceptualize the actual process, approaching the current scientific knowledge and integrating various phases of the Wilson cycle. For future applications, we describe the scientific assumptions, the relationship between physical and scientific models, and suggest methods and contexts of learning, in order to apply these experiences, as well as scenarios of current and past geological settings.
\end{abstract}

\section{Introdução}

A formação de montanhas sempre suscitou o interesse da humanidade, levando à formulação de diversas e sucessivas teorias explicativas de acordo com o conhecimento e controvérsias de cada época.

No início do século XIX, a Geologia começava a individualizar-se como ciência autónoma, integrando ramos do conhecimento como a cristalografia, a mineralogia ou a estratigrafia (Laudan 1987, Newcomb 2009). Tendo por base inicial o trabalho no campo, que incluía observações, recolha de materiais, medições de estruturas, o geólogo James Hutton [1726-1797] propunha, nessa época, a teoria plutonista da Terra. Esta teoria passava a explicar não só sucessões de estratos, como já fazia a teoria neptunista, mas conseguia igualmente explicar discordâncias angulares, intrusões ígneas e estruturas de deformação observadas no campo. Um dos cientistas que acompanhou James Hutton nas suas observações no campo foi James Hall de Dunglass [1761-1832]. Este cientista, possivelmente devido à influência de Lavoisier (Newcomb 2009), interessou-se por reproduzir, em labo- ratório, a formação de estruturas que observava no campo, estabelecendo relações causa-efeito e, consubstanciando as explicações de James Hutton, apesar da desconfiança deste face à experimentação (Newcomb 2009, Brandstetter 2011).

Entre todos os processos geológicos que Hall tentou simular, aquele que viria a ser mais repetido e depois melhorado, marcando definitivamente a metodologia desta área da Geologia, a Tectónica Experimental, foi a compressão (Ranalli 2001, Oreskes 2007). Primeiro utilizou tecidos e, mais tarde, argilas para simular os estratos geológicos sujeitos a deformação (Newcomb 2009).

A experimentação (ou modelação) análoga, principalmente de processos compressivos começava assim a estabelecer-se com James Hall, tendo sofrido vários aperfeiçoamentos a partir do final do século XIX até à atualidade, consoante as teorias explicativas que foram enquadrando os processos simulados mas, principalmente, em virtude do rigor que foi sendo exigido para que o processo experimental se aproximasse o mais possível do processo real simulado (Bolacha 2014). 
No Ensino, a ideia da utilização das chamadas caixas de areias (sandbox) bem como outras atividades de Geologia Experimental julga-se ter surgido em vários países no início do século XX a par do incremento da investigação (Graveleau et al. 2012). Quer em Portugal (Carvalho \& Moura 1928) quer no Brasil (Carvalho 2011), estas atividades experimentais começaram a ser divulgadas (ou mesmo realizadas nas aulas de Geografia) ainda na primeira metade do século. No entanto, em Portugal, quer na investigação como no ensino, o seu conhecimento efetivo só viria a acontecer a partir dos anos 80 (Mota 2011).

O mecanismo subjacente às caixas de areias consiste, em geral, na deformação por compressão, através do movimento tangencial de uma prensa, parede ou cunha (Fig.1), de um conjunto de camadas de areias previamente dispostas e separadas (a na figura 1), ou não, por uma camada de pó de rocha (e.g. gesso, cimento etc.). O pó de rocha, ou camadas mais finas de areias com cores diferentes, é utilizado para evidenciar as estruturas formadas (principalmente falhas), tendo a função de marcador cinemático.

O principal objetivo didático em que assenta a utilização das tradicionais caixas de areias costuma ser a visualização de estruturas análogas às geológicas observadas no campo (Fig. 2). Porém, mais do que para uma simples simulação da formação daquelas estruturas, este tipo de mecanismo pode ser utilizado para simular a formação de cadeias de montanhas dentro de um determinado enquadramento teórico, tal como tem sido realizado na investigação em Tectónica Experimental, desde o século XIX (Oreskes 2007, Graveleau et al. 2012).

Outro tipo de equipamento surgiu após a generalização da Teoria da Tectónica de placas. Tem como objetivo principal estudar a cinemática e a evolução estrutural dos prismas acrecionários formados nas zonas externas das cadeias de montanhas, associados a zonas de subdução (Davis et al. 1983, Graveleau et al. 2012). Igualmente constituído por uma caixa de vidro acrílico, contrariamente às tradicionais caixas

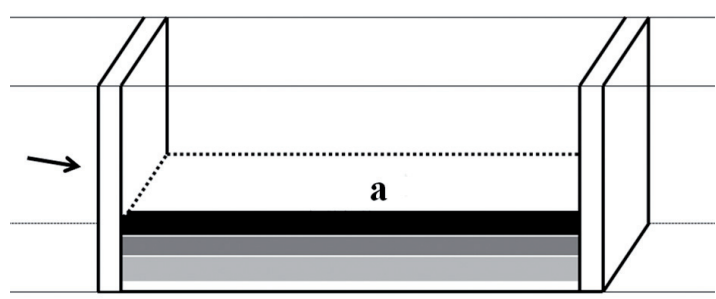

Figura 1. Desenho esquemático de um equipamento para deformação de uma multicamada de areias por compressão, simulando a colisão continental. As duas paredes situadas no interior da caixa simulam as margens dos continentes. Uma das paredes permanece fixa enquanto a outra se movimenta no sentido da seta. a- multicamada de areias

de areias, não apresenta, em geral, paredes nos topos (Fig. 3). Possui apenas uma cunha ou parede fixa num dos topos (b na figura 3), por baixo da qual é puxada uma folha de acetato, que simula uma placa em subdução, tão larga quanto o fundo da caixa e abrangendo todo o seu comprimento (c na figura 3). As areias são distribuídas camada a camada em cima do acetato, até formar uma multicamada de areias semelhante à esquematizada na figura 1. A friç̧ão da folha de acetato influenciará o padrão estrutural do prisma (e.g. Bose et al. 2009). Outros autores utilizam como folha basal, materiais como mylar, plástico, lixa (Graveleau et al. 2012) ou papel vegetal (Crespo-Blanc \& Luján 2004).

A cunha (b na figura 3) contra a qual a multicamada de areias vai sendo deformada à medida que a folha basal é puxada, representa a margem do continente ou parte da cadeia de montanhas anteriormente formada.

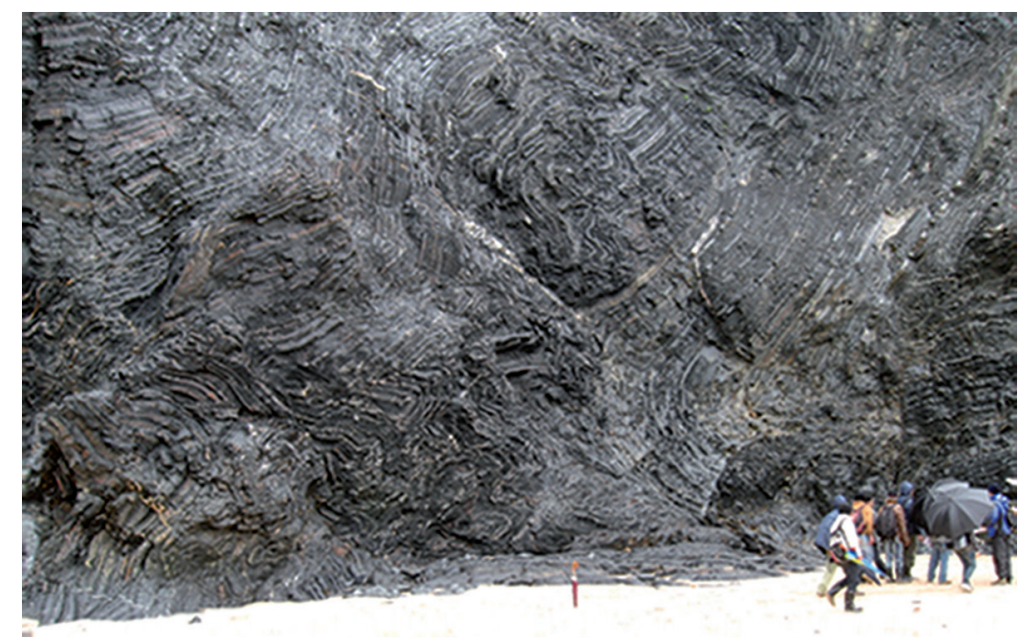

Figura 2. Exemplo de estruturas geológicas cuja formação pode ser simulada numa vulgar caixa de areias. Zona de grande deformação com estruturas formadas durante a orogenia varisca, Costa Vicentina, SW de Portugal 


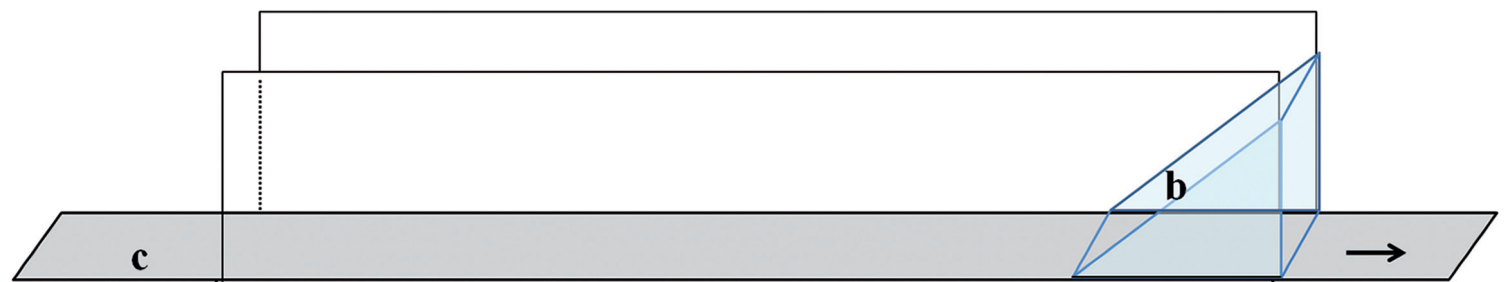

Figura 3. Desenho esquemático de um equipamento para deformação de uma multicamada de areias por compressão associada à subdução; b- cunha, c- folha de acetato. A seta representa o sentido de tração do acetato

Apesar de este tipo de equipamento possibilitar igualmente a observação e análise de estruturas, é, com efeito, especialmente vantajoso para evidenciar o processo de formação das zonas externas das cadeias de montanhas associado a uma zona de subdução. Assim, em contextos de aprendizagem (aula, museu de Ciência, etc.), relativamente às tradicionais caixas de areia ou, em conjunto com elas, o equipamento esquematizado na figura 3 , tem não só a vantagem de evidenciar as fases de colisão da orogénese, como também as fases mais precoces de deformação durante a subdução oceânica e/ou continental. Para além disso, permite perceber como, a partir de uma bacia oceânica que entra em processo de fecho, se forma uma cadeia de montanhas, ou seja, contextualizar a orogénese no ciclo de Wilson.

O ciclo de formação e fecho dos oceanos tem este nome em homenagem ao geofísico canadense Tuzo Wilson (1908-1993), um dos autores da Teoria da Tectónica de placas. Wilson sugeriu, com base em exemplos atuais, que um oceano, após formação e alastramento da litosfera oceânica, começa a fechar por subdução, tendo como consequência a construção de uma cadeia de montanhas, culminando com a colisão continental (Wilson 1966). No processo de ensino do conceito "formação de cadeias de montanhas", nem sempre este é explicado desta forma, centrando-se geralmente apenas na fase final de colisão continental.

Os resultados de uma investigação educacional realizada (Bolacha 2014) em contextos de aprendizagem formal e não formal (Gadotti 2005, Gohn 2006, Morand-Aymon 2007), utilizando uma metodologia de estudos de caso múltiplos (Stake 2006, 2012) com alunos portugueses pré-universitários $\left(11^{\circ}\right.$ e $12^{\circ}$ anos), revelaram ser mais comum a ideia da formação de cadeias de montanhas por colisão em ambiente de convergência de placas, sem prévia subdução de placa (oceânica ou continental). No entanto, as conceções dos mesmos alunos parecem ser modificadas após a simulação da formação de uma cadeia de montanhas (zona externa) através do modelo de subdução acima referido (Bolacha 2014). Com efeito, a maioria dos alunos que participaram nestes três estudos de caso, dois realizados com alunos em aula regular (contexto formal), e outro com alunos em visita a um Museu de Ciência (contexto não formal), passou a considerar a subdução como processo inerente à formação de cadeias de montanhas associado à convergência de placas.

Deste modo, na sequência dos resultados dos estudos referidos e das potencialidades que este tipo de experiências apresenta para a compreensão da formação de cadeias de montanhas no contexto da Teoria da Tectónica de placas, fazem-se algumas propostas utilizando o mesmo equipamento e sugerindo como podem e devem ser exploradas em qualquer contexto de aprendizagem.

\section{A experimentação análoga: da investigação para 0 ensino}

O professor ou divulgador ao utilizar estes equipamentos deve, antes de mais nada, estar consciente dos objetivos de aprendizagem pretendidos. Para isso, deve saber que produzirá não só uma modelação física e experimental, mas uma simulação de um processo geológico para que o seu público-alvo compreenda este último, neste caso a formação de uma cadeia de montanhas. Compreender processos geológicos através de uma simulação passa pelo estabelecimento de raciocínios de causalidade e pela extrapolação do processo simulado para o processo real. Assim, o modelador pretenderá, que o processo visual se aproxime o mais possível do que ocorre na natureza. É essa a grande vantagem desta metodologia, ou seja, permitir simular com materiais simples, mas dinamicamente análogos, um processo que não pode ser vivido. Isto porque estes processos (de formação de cadeias de montanhas) decorrem em unidades de espaço e tempo enormes à escala humana. Para além disso, no campo só se observam os produtos finais de todo o processo, tendo sido obliterados 
todos os outros que foram sendo transformados ao longo do tempo.

$\mathrm{Na}$ modelação, quer o processo quer os materiais utilizados devem ser análogos aos geológicos. Isto significa que apesar das limitações que se impõem e, tendo em conta que se trata de uma aplicação didática em que é assegurado o rigor científico, devem os materiais análogos ter um comportamento reológico (comportamento face à deformação) semelhante ao dos materiais geológicos, ao longo do tempo durante o qual sofreram deformação (e.g. Crespo-Blanc \& Luján 2004). Neste sentido, as areias são os materiais considerados como os que melhor se assemelham às rochas supracrustais por satisfazerem o critério de fraturação de Coulomb (Hubbert 1951, Byerlee 1978). Algumas relações de escala, como as geométricas e as cinemáticas que se estabelecem entre o modelo e o objeto real (e.g. Hubbert 1937), são obrigatórias na investigação, devendo igualmente ser estabelecidas na aplicação didática, facilitando a extrapolação do modelo para a realidade e a consequente compreensão do fenómeno real. Assim, se a finalidade for a compreensão de um determinado fenómeno regional, relacionado com um certo objeto geológico como, por exemplo, a formação do prisma acrecionário da Zona Sul Portuguesa (Bolacha 2014) ou de um diapiro magmático como, por exemplo, a Serra de Sintra, perto de Lisboa (Fonseca et al. 2001, Bolacha et al. 2012), poderá ser importante aplicar uma escala geométrica quantitativa no dimensionamento do equipamento/modelo. Este cuidado é particularmente importante no que diz respeito ao comprimento para os prismas acrecionários. A utilização de materiais com comportamento reológico adequado aos dos materiais reais, para qualquer um dos processos, é igualmente um aspeto a ter em conta.

Para ajudar a uma efetiva extrapolação, a experiência deve ser acompanhada ou precedida da exploração de mapas geológicos da região em estudo onde se situa o objeto geológico cuja formação é simulada (Crespo-Blanc e Luján 2004, Bolacha et al. 2012, Bolacha 2014). É sempre bom não esquecer que qualquer modelo utilizado no Ensino das Ciências não funciona por si só, devendo sempre ser acompanhado de outros modelos ou recursos

educativos (Gilbert \& Ireton 2003).

A partir dos anos 80 , os mecanismos de formação das cinturas orogénicas ativas, como os sopés dos Himalaias e a zona ocidental de Taiwan, e os prismas acrecionários submarinos, como o do Nankai no Japão ou da margem continental do Perú (e.g. Kukowski et al. 1994), passaram a ser comparados ao dos prismas que se formam na frente de limpa-neves em movimento (Fig. 4). Os prismas de neve, ou de solo, possuem as mesmas propriedades físicas, mas a uma escala menor. $\mathrm{O}$ solo, a neve ou as rochas deformam-se, formando um prisma até que este atinja uma forma crítica e comece a deslizar, continuando a crescer de forma auto similar se mais material for acrescentado à sua frente (Davis et al. 1983).

Estes autores utilizaram um mecanismo do tipo de subdução para simular a formação dos prismas acrecionários, cujos pressupostos são semelhantes aos do representado na figura 3 . Este equipamento (Davis et al. 1983) permitiu, deste modo, apoiar a relação genética entre os prismas acrecionários submarinos e as zonas externas das cadeias orogénicas, bem como a associação de ambos aos limites convergentes de placas. Tal como para as tradicionais caixas de areias, os cientistas utilizam esta forma de modelação para averiguar a plausibilidade de relações causa-efeito, ou seja, de relações entre as forças aplicadas e as estruturas produzidas.

Neste caso, não existe necessidade de se estabelecer relação de escala relativa ao fator tempo e, consequentemente, relativa à velocidade, dado que o comportamento reológico das areias é indepen- 
dente desse fator (e.g. Lallemand et al. 1992).

Como qualquer modelo, estes representam uma realidade, ou seja, fenómenos e objetos geológicos de forma muito simplificada, logo importa discutir sempre as suas limitações (e.g. Justi 2009), seja o modelo construído ou não pelos próprios alunos. Em qualquer modelo do tipo acima descrito são, por exemplo, menosprezados a subsidência da placa e o consequente reajuste isostático, bem como o papel dos fluidos na deformação (e.g. Lújan et al. 2003). A velocidade do movimento, como justificámos atrás, não necessita ser quantificada, assumindo-se que deve ser baixa de modo que a formação das estruturas seja observável. Para além das limitações apontadas devem ser abordadas e discutidas com os alunos, ou entre eles, de acordo com o seu nível etário, outras como o atrito das paredes laterais que diminui a velocidade de propagação da deformação na periferia relativamente ao centro do prisma acrecionário, modificando a forma da estrutura. Esta limitação é, no entanto, compensada pelo facto de assim ser possível uma observação da deformação passo a passo, caso contrário, só no final a mesma seria possível e, apenas através da produção de cortes como é realizado, por exemplo, em López e Crespo-Blanc (2008).

Tal como para os geólogos, deve ser exigido aos alunos, quando visualizam a modelação de um fenómeno geológico decorrido em largas unidades de espaço e tempo, que realizem um tipo de raciocínio por analogia, tão próprio da geologia (Schumm 1991). Este tipo de raciocínio exige a consciencialização plena das semelhanças e diferenças entre a analogia (ou o modelo) e a realidade (Dagher 1998, Jee et al. 2010, Duarte 2005). Só assim podem perceber a natureza da analogia ao nível da abstração (Gilbert 2004).

Antes de iniciar a atividade, o professor ou divulgador deve ter em mente os objetivos que pretende que os alunos, ou o seu público-alvo, atinjam. Os objetivos devem situar-se não só ao nível da aprendizagem de conteúdos, mas também das

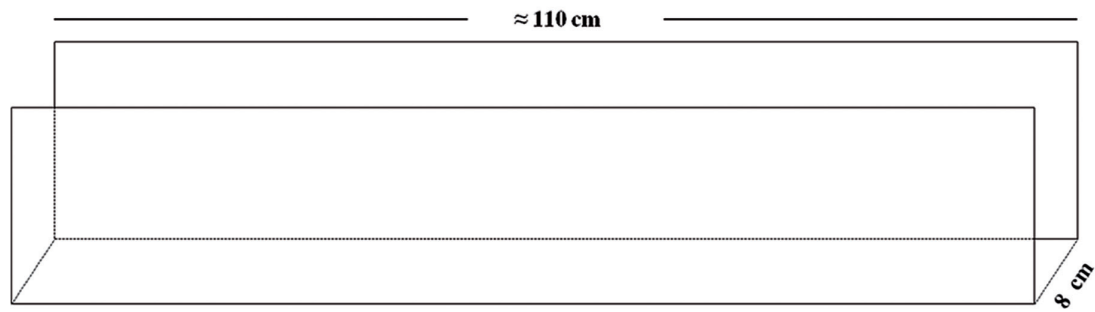

Figura 5. Equipamento utilizado em todas as experiências. Caixa com paredes em vidro acrílico, aberta nos topos. Espessura das paredes $\approx 1 \mathrm{~cm}$ caraterísticas da Ciência (Matthews 2012). Assim, ao nível das características da Ciência (objetivos epistemológicos) e, apenas por simples visualização ou pondo as "mãos na massa", os alunos devem ser levados a compreender que a experimentação análoga é uma metodologia própria da investigação em Geologia, particularmente, da Geodinâmica, sendo hoje relevante para a construção do seu conhecimento. Outros objetivos inerentes às características da Ciência, relacionam-se com a aprendizagem do que são modelos científicos, da sua contextualização histórica, bem como das relações entre eles e a realidade que representam.

Ao nível do conhecimento científico, consoante o nível etário e o grau de conhecimento pretendido, as experiências que se descrevem podem apenas demonstrar processos de formação de cadeias de montanhas e estruturas associadas, ou também ilustrar, de uma forma simplificada, como se forma uma cadeia de montanhas no contexto dos ciclos de Wilson, contemplando a subdução e a colisão continental.

Para uma efetiva extrapolação para o processo real que é simulado, aconselha-se a escolha de um exemplo o mais próximo possível dos alunos, fornecendo condições à concretização de uma aprendizagem verdadeiramente significativa (Novak e Gowin 1996, Orion 2007). De modo a facilitar a extrapolação, será aconselhável, se tal for possível, a realização de uma saída de campo, antes ou após a modelação. Pode ser motivadora e permitir uma maior contextualização do fenómeno geológico.

\section{Materiais, métodos e técnicas}

Com um único equipamento (Fig. 5) é possível produzir vários modelos de formação de cadeias de montanhas: os que se inserem no modelo clássico com um equipamento do tipo caixa de areias, que simula a colisão continental, e os que simulam a compressão associada à subdução ou mesmo fazendo a ponte entre os dois tipos, de modo a mimetizar o processo orogénico desde o início da subdução até à colisão continental, consoante os objetivos de aprendizagem. O equipamento é constituído por uma caixa com paredes transparentes, aberta nos topos.

Assim, se o objetivo 


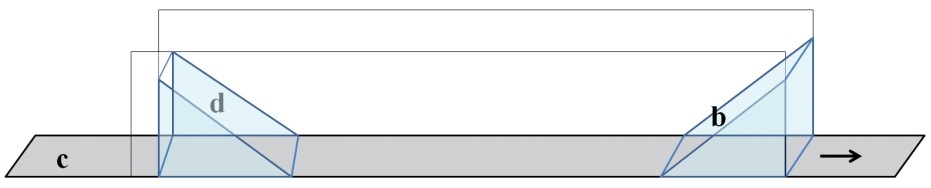

Figura 6. Equipamento para simular a deformação por subdução e colisão. b- cunha simulando a margem ativa do continente, c- acetato simulando a placa em subdução, d- cunha simulando a margem passiva do continente oposto

for apenas simular a formação de montanhas por colisão continental basta, utilizando o equipamento representado na figura 5 , colocar duas paredes de um material que não risque o vidro acrílico como a esferovite de cor branca (poliestireno expandido) ou de cor azul, utilizada como isolante térmico na construção civil (poliestireno extrudido); fixá-las inicialmente, e despejar ou polvilhar, camadas de areia de cores diferentes. A areia utilizada deve ser bem calibrada, homogénea, com um ângulo de atrito $(\varnothing)$ de cerca de $30^{\circ}$. A multicamada de areias deverá ter cerca de $2 \mathrm{~cm}$. Deixar fixa uma das paredes, e mover lentamente a outra, comprimindo toda a multicamada na direção da parede que ficou fixa. A extrapolação pode ser feita para o exemplo atual mais conhecido, a cadeia dos Himalaias, no entanto, a utilização de outros análogos regionais, mesmo que sejam mais antigos mas geograficamente próximos dos alunos, poderá servir como forma de motivação (Orion 2007, Bolacha 2014).

Se o objetivo for a simulação do processo de formação de uma cadeia de montanhas associado a uma zona de subdução, no mesmo equipamento deverá ser colocada uma cunha por baixo da qual passará o acetato que simula a placa em subdução. Sobre ele assentará a multicamada de areias que, após tração do acetato, sofrerá deformação contra a cunha. Se, para além do objetivo referido, for importante simular também a influência do outro continente na deformação e, consequente colisão, no final do acetato, por oposição à primeira cunha, deverá ser fixada uma outra cunha a simular o continente situado na margem oposta do oceano que está se fechando (Fig. 6). A inclinação das cunhas simula o declive das margens continentais.

Para o caso de se pretender simular apenas a subdução, a extrapolação poderá ser feita por exemplo, para a formação da Zona Sul Portuguesa (no Sudoeste da Península Ibérica) e do fecho do Oceano Rheic, no final do Paleozoico (Bolacha 2014). Na situação em que é também simulada a colisão como consequência da subdução, a extrapolação pode ser feita para os Himalaias, como consequência do fecho do Mar de Tétis e da convergência das placas indiana e euroasiática. Em qualquer das situações descritas, a experimentação deve ser precedida ou acompanhada, por exemplo, por imagens, não importa o suporte (papel ou digital), estruturas observadas no campo e/ou no Google Earth ${ }^{\circledR}$, ou de mapas geológicos, pois os modelos não funcionam isoladamente.

Seguem-se alguns resultados possíveis das experiências sugeridas. Em todas se dispôs inicialmente uma multicamada de areias de várias cores. A areia branca é original, enquanto as outras foram coloridas a partir dessa, utilizando corante de roupa. A areia é normalmente polvilhada (Fig. 7), utilizando um caneleiro (utilizado em doçaria fina) para melhor distribuir a areia, evitando uma compactação diferencial no caso de ser despejada e alisada.

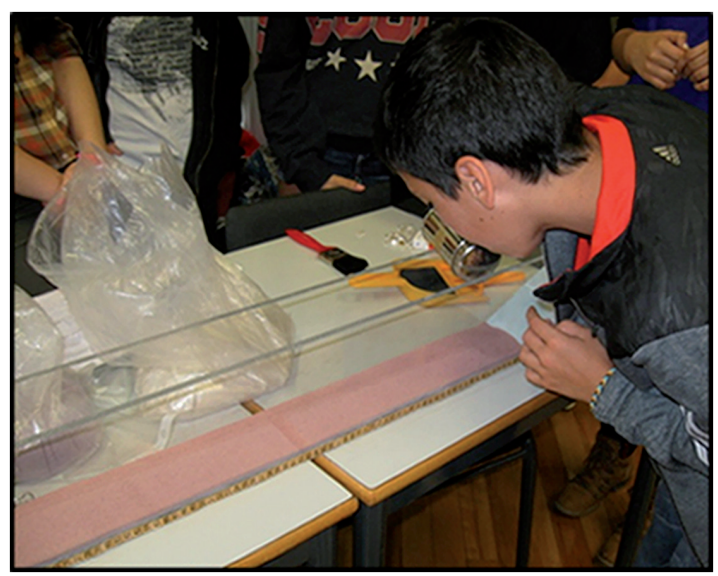

Figura 7. Aluno do $7^{\circ}$ ano (Escola Secundária de D. Dinis, Lisboa) polvilhando a areia sobre a folha de acetato

$\mathrm{Na}$ ausência de um caneleiro pode o mesmo ser substituído por um simples passador ou coador (e.g. Crespo-Blanc \& Luján 2004). Nunca é demais repetir que a areia utilizada deve ser homogénea e bem calibrada. Sendo fina, as estruturas formadas (falhas e dobras) ficam mais evidentes. Utilizou-se, nestas experiências, preferencialmente a areia branca como marcador cinemático.

\section{Apresentação de resultados}

Na primeira experiência, clássica de colisão continental, a deformação induzida pela compressão da parede movível, progride no mesmo sentido do movimento desta (o sentido da seta na figura 8). As falhas formadas inclinam-se no sentido oposto e 
resultam da ruptura, pelo flanco inverso, das dobras formadas, originando a sobreposição das camadas. Os cavalgamentos vão-se sucedendo no sentido do deslocamento da parede, ou seja, da esquerda para a direita. A partir de certa altura (B), ainda sem influência da parede situada no lado direito da figura, o prisma formado atinge a sua inclinação crítica, começando a colapsar, visível pelo rolamento de alguns grãos de areia. Também à medida que a deformação progride (A-B-C), os cavalgamentos formados vão-se inclinando mais. A influência da parede, que simula o continente hipoteticamente fixo, contra a qual se dá a compressão (em C), induz
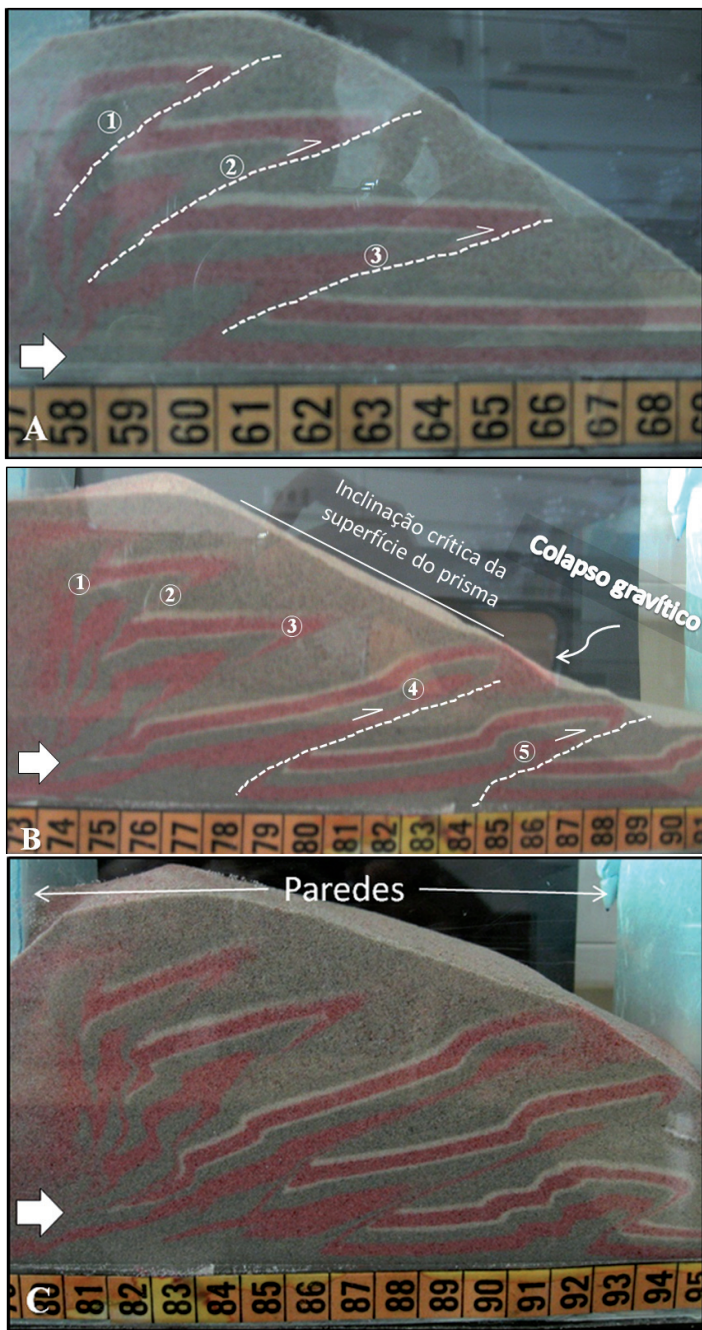

Figura 8. Alguns episódios da experiência de colisão (realizada no LabGExp/FCUL). A- conjunto de cavalgamentos formados por compressão após $7 \mathrm{~cm}$ de deslocação da parede situada no lado esquerdo da figura. B- progressão de deformação e da forma do prisma. C- situação final. É visível a sobreposição de estratos por dobramento e ruptura pelo flanco inverso. A seta representa o sentido da compressão um maior espessamento no final da experiência. Este, mais do que quadruplicou. A percentagem de encurtamento final é também bastante elevada.

Na segunda experiência, é simulada unicamente a deformação decorrente da subdução da placa (oceânica ou continental) onde se depositaram os sedimentos. Marcou-se no vidro um risco azul para simular o nível do mar, de modo que os alunos compreendam que o processo real decorre dentro de água.

A deformação propaga-se a partir da cunha (parte da cadeia de montanhas já formada), no lado direito da figura, e acontece contra ela à medida que o acetato é puxado. Os cavalgamentos formados pendem, predominantemente, no sentido oposto ao da propagação da deformação. A sua inclinação ou pendor vai diminuindo da cunha para a zona externa. No entanto, à medida que prossegue a deformação, a inclinação dos cavalgamentos mais internos, já formados, vai aumentando, como se constata pelo ângulo marcado nas figuras (Fig. 9 $-\mathrm{A}, \mathrm{B}$ e C).

À superfície, ou em planta, observa-se a rutura superficial, expressão dos cavalgamentos (Fig. 9 A, B e C).

Na terceira experiência (Fig. 10), a deformação tem início primeiro junto às duas cunhas, parando em seguida junto à cunha que representa a margem continental passiva (à esquerda na imagem), propagando-se essencialmente a partir da cunha que representa a margem continental ativa (à direita na imagem). O padrão estrutural é, durante os primeiros incrementos de deformação, semelhante ao da experiência anterior (vide figuras 9 A e 10 A), aumentando a complexidade da deformação a partir do momento em que acontece a interferência das estruturas produzidas contra a cunha do lado esquerdo com as que foram sendo produzidas a partir da cunha situada no lado direito da figura (Fig. 10 - B e C).

\section{Análise e interpretação de resultados}

A percentagem de encurtamento final na primeira experiência (Fig. 8) é bastante elevada, evidenciando um empilhamento de leitos que é semelhante e comparável aos grandes mantos de carreamentos que se observam nas cadeias alpinas onde foram inicialmente estudados (e.g. Merle 1998, Mattauer 1973). Esta experiência coloca igualmente em maior evidência a relação genética entre dobras e falhas (cavalgamentos), bem como 


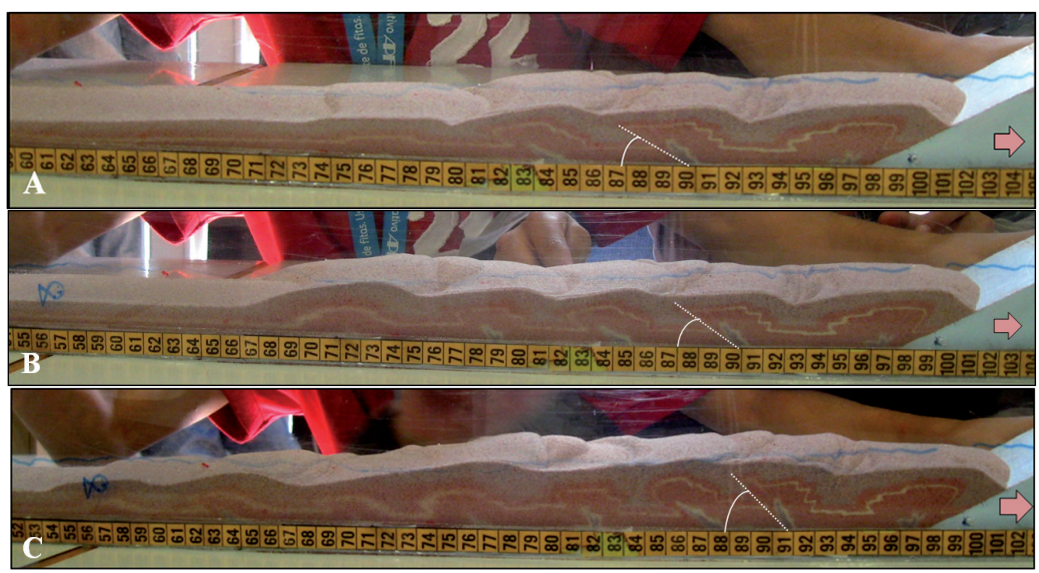

Figura 9. Experiência de compressão por subdução, montada por alunos, Escola Secundária D. Dinis, Lisboa. A propagação da deformação faz-se no sentido oposto ao do movimento da folha de acetato basal, representado pela seta. De $\mathrm{A}$ para $\mathrm{C}$ o pendor dos cavalgamentos formados (marcado nas figuras) na zona interna do prisma vai aumentando

a teoria da forma crítica no prisma (vide figura 4). O prisma vai crescendo até determinada altura a partir da qual começa a ocorrer o rolamento de alguns grãos de areia, mantendo-se a mesma inclinação de superfície a partir daí. Esta só começa a modificar-se quando sofre influência da pressão da parede que se manteve fixa, que simula o continente que hipoteticamente se manteve na mesma posição.

Na segunda experiência (Fig. 9), a estruturação (tipo de estruturas e inclinação) final é comparável à zona externa de uma cadeia de montanhas. Pode ser utilizado o exemplo da cadeia varisca (Ribeiro et al. 1979) para simular a formação de zonas externas como a Zona Sul Portuguesa, que abrange parte do Alentejo, a Serra Algarvia em Portugal e o SW de Espanha. Nesta zona paleogeográfica da Península Ibérica, as estruturas são progressivamente mais inclinadas de NE para SW, ou seja, do interior para o exterior da zona. A realização da extrapolação para a formação desta zona da cadeia varisca deve sempre ter em conta as limitações do modelo (Bolacha 2014).

$\mathrm{Na}$ terceira experiência (Fig. 10), o aspeto que pode ser considerado mais relevante é a deformação atingir uma grande complexidade, por terem sido aplicadas forças que atuam em sentido contrário às que atuavam apenas na segunda experiência, ou seja, contra a cunha situada no lado direito das figuras. Ao serem induzidos novos incrementos de deformação, o espessamento aumenta, assim como a complexidade da deformação, que pode ser comparada com a fase final visível da orogenia varisca, por exemplo, em algumas praias da Costa Vicentina, no SW de Portugal (Fig. 2).

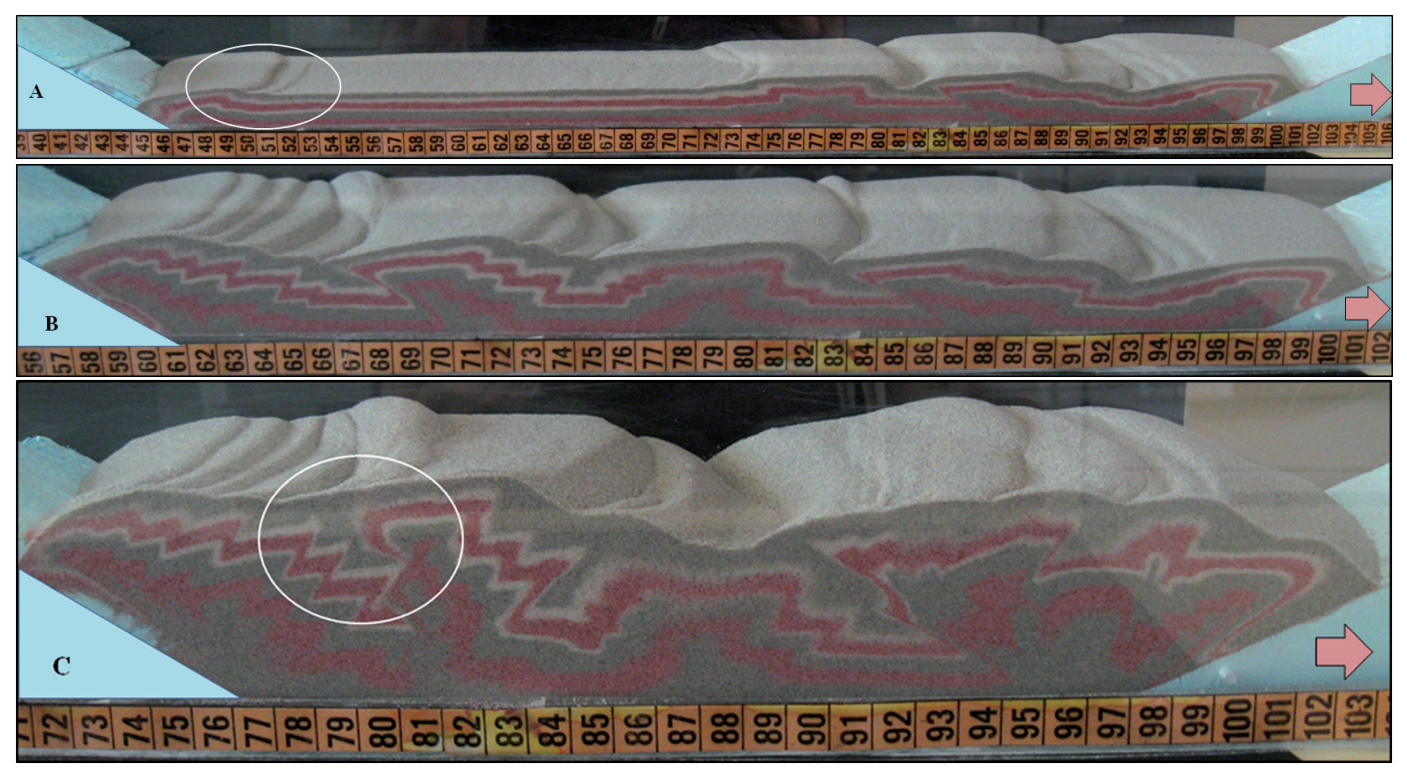

Figura 10. Experiência de compressão por subdução com colisão, realizada no LabGExp/Centro de Geologia da Faculdade de Ciências da Universidade de Lisboa. A- Deformação resultante dos primeiros incrementos de tração do acetato. B- A deformação após os primeiros incrementos de deformação começa a fazer-se sentir mais intensamente a partir da cunha situada no lado esquerdo da figura. C- Aspeto final da experiência. A circunferência evidencia a zona de interferência da deformação. A seta representa o sentido do movimento do acetato 


\section{Considerações finais}

Em qualquer uma das experiências descritas e analisadas, para além da simples observação qualitativa, é possível medir distâncias, ângulos, efetuar diversos cálculos simples para melhor evidenciar as relações entre a diminuição do espaço horizontal, ou seja do encurtamento, e o aumento do espaço vertical, ou seja, do espessamento, também na perspetiva da aplicação matemática (Bolacha et al. 2013). A influência dos chamados fatores externos na taxa de encurtamento, como a alteração e erosão das rochas pode e deve ser também discutida (Graveleau e Dominguez 2008, Bolacha 2014) como fatores que estão ausentes das experiências, visto que a modelação simplifica drasticamente os processos naturais e as formas como interatuam. É preciso não esquecer que os processos naturais são extremamente complexos, nem sempre são contínuos, variando a sua velocidade ao longo do tempo e do espaço, e nas diversas escalas (Bolacha et al. 2013).

As experiências descritas podem ser desenvolvidas em qualquer espaço, contexto e nível de ensino, com diversos graus de aprofundamento dos conteúdos. Podem ser realizadas isoladamente ou em sequência, de modo a evidenciar alguns dos episódios de deformação que ocorrem durante o fecho de um oceano.

Partiu-se da ideia da colisão continental exemplificada pela primeira experiência com o objetivo de alargar a forma de abordagem a um conceito mais abrangente de formação de cadeias de montanhas. A colisão é a forma mais comum de concetualizar a formação de cadeias de montanhas, contudo pode ser uma forma simplista se não for bem enquadrada na Teoria da Tectónica de placas e se não for acompanhada de exemplos reais.

Assim, considerou-se que a segunda e a terceira experiências, em conjunto com a primeira, ou separadamente, podem promover uma concetualização da formação de cadeias de montanhas mais consentânea com a atual Teoria da Tectónica de placas e o modelo dos ciclos de Wilson. Caberá ao modelador adaptar as experiências aos seus objetivos de aprendizagem e aos objetos e fenómenos geológicos para os quais pretenda efetuar a devida extrapolação.

Por fim, é importante assegurar uma efetiva discussão das limitações e a averiguação de que o público-alvo entendeu bem as semelhanças e diferenças entre modelo e realidade. Isto é imprescin- dível para uma efetiva aprendizagem dos processos simulados e não apenas dos modelos, evitando-se a construção de conceções erróneas ou de modelos mentais demasiado simplistas que, dificilmente, poderão, mais tarde, aproximar-se dos modelos científicos mais atuais.

\section{Agradecimentos}

Parte das experiências descritas teve lugar no Laboratório de Geologia Experimental, Departamento de Geologia, Faculdade de Ciências da Universidade de Lisboa. Outra parte decorreu na Escola Secundária D. Dinis, Lisboa, com colaboração de alguns alunos do $7^{\circ}$ ano de escolaridade, em Maio de 2014.

Os resultados dos estudos de caso referidos foram obtidos em trabalho de doutoramento financiado pela Fundação para a Ciência e a Tecnologia através da bolsa ref ${ }^{a}$ SFRH/BD/43297/2008.

A autora agradece as críticas e sugestões dos avaliadores Profs. Doutores Zorano Sergio de Souza da Universidade Federal do Rio Grande do Norte, e Lázaro Valentim Zuquette da Universidade de S. Paulo (USP), Campus de São Carlos, SP., bem como dos editores da revista que em muito contribuíram para a versão final do artigo.

\section{Referências}

Bolacha E. 2014. Modelos de dinâmica da Terra aplicados à Geologia de Portugal: relevância da experimentação análoga no ensino e na divulgação da Geologia. Lisboa: Depart. Geologia. Fac. Ciências. Universidade de Lisboa. 686 p. (Tese Dout.).

Bolacha E, Deus H. M., Cruces A. 2012. Serra de Sintra - Casa das Ciências.org. Portal Gulbenkian para Professores. http://casadasciencias.org./ >.Acesso: 26.04.2015.

Bolacha E., Deus H. M., Cruz I., Fonseca P. E. 2013. Descobrir o planeta Terra: o Tempo e o Espaço em Geologia. Educação e Matemática.,122:13-19.

Bose S., Manda N., Mukhopadhyay D., Mishra P. 2009. An unstable kinematic state of the Himalayan tectonic wedge: Evidence from experimental thrust-spacing patterns. Journal of Structural Geology, 31: 83-91.

Brandstetter T. 2011. Time Machines: Model Experiments in Geology. Centaurus, 53:135-145.

Byerlee J. 1978. Friction of rocks. Pure and Applied Geophysics PAGEOPH, 116:615-626.

Carvalho A. 2011. Apparelhos para o Ensino do Relevo: A influência da Geologia Experimental no Praticas de Geographia (1930). URL < http://www. 
educasul.com.br/2011/evento_anais_formacao. html > .Acesso: 26.04.2015.

Carvalho A. F., Moura F. M. 1928. Geodinâmica, Geotectónica e Geognosia, Primeiro livro de Geologia. Coimbra: Moura Marques \& Filho.

Crespo-Blanc A., Luján M. 2004. Como se forman las Montañas: Enseñanzas del Laboratorio. Enseñanza de las Ciencias de la Tierra, 12 (1): 83-87.

Crespo-Blanc A., Murcia López M. I. 2008. La Formación de Oceanos y Cadenas de Montanas a partir de Modelos Analógicos: Maquetas y Nuevos Materiales. 2008. Enseñanza de las Ciencias de la Tierra, 16 (2): 173-177.

Dagher Z. 1998. Case for analogies in teaching science for understanding. In Mintzes J. J., Wandersee J. H., Novak J. eds. Teaching Science for Understanding San Diego: Academic Press. p. 195-211.

Davis D., Suppe, J., Dahlen, F. A.1983. Mechanics of Fold-and-Thrust Belts and Accretionary Wedges. JGR Solid Earth, 88 (B2): 1153-1172.

Duarte, M. C. 2005. Analogias na Educação em Ciências. Contributos e Desafios. Investigações em Ensino das Ciências, 10 (1): 7-29.

Fonseca P. E., Ribeiro L. P; Caranova R., Filipe P. 2001. Experimentación analógica sobre el desarollo de un diapiro y la deformación producida en las rocas encajantes. Enseñanza de las Ciencias de la Tierra, 9 (3):270-276.

Fossen H. 2010. Structural Geology. Cambridge: Cambridge Univ. Press.

Gadotti M. 2005. A questão da educação formal/ não formal. Institut Internacional des Droits de l'Enfant (IDE). Droit à l'éducation: solution à tous les problèmes ou problème sans solution? Sion (Suisse), 18 au 22 octobre, 1-11. URL < http://www.virtual.ufc.br/solar/aula_link/llpt/A_a_H/estrutura_politica_gestao_organizacional/aula_01/imagens/01/Educacao_Formal_Nao_Formal_2005. pdf> . Acesso: 31.08.2014.

Gilbert J. 2004. Models and Modelling: Routes to More authentic Science Education. IJSME, 2: 115-130.

Gilbert S. W.\&s D., Suppe, J. \&utoramento..., Ireton S. W. 2003. Understanding Models in Earth and Space Science. Arlington: NSTApress.

Gohn M. G. 2006. Educação não-formal, participação da sociedade civil e estruturas colegiadas nas escolas. Rio de Janeiro, Scielo. Educ. 14: 27-38. URL < http://scielo.br/pdf/ensaio/v14n50/30405. pdf. Acesso 31.08.2014.

Graveleau F., Dominguez S. 2008. Analogue modelling of the interaction between tectonics, erosion and sedimentation in foreland thrust belts. Tectonics. C. R. Geoscience, 340:324-333.

Graveleau F., Malavieille J., Dominguez S. 2012. Experimental modelling of orogenic wedges: A review. Tectonophysics, 538-540:1-66.
Hubbert M. K. 1937. Theory of scale models as applied to the study of geological structures. Bull. Geol. Soc. Am. 48:1459-1520.

Hubbert M.K. 1951. Mechanical basis for certain familiar geologic structures. Geol. Soc. Am. Bull. 62:356-372.

Jee B. D., Uttal, D. H., Gentner D., Manduca C., Shipley T. F., Tikoff B., Ormand C. J., Sageman, B. 2010.Commentary: Analogical Thinking in Geoscience Education. JGE, 58 (1): 2-13.

Justi R. 2009. Learning how to model in science classroom: key teacher's role in supporting the development of students' modelling skills, Educación Química, 20: 32-40.

Kukowski N., Huene R., Malavieille J., Lallemand S. 1994. Sediment accretion against a buttress beneath the Peruvian continental margin at 12 oS as simulated with sandbox modelling. Geol Rundsch, 83: 822-831.

Lallemand S., Malavieille J., Calassou S. 1992. Effects of Oceanic Ridge Subduction in Accrecionary Wedges: Experimental Modeling and Marine Observations. Tectonics, 11 (6): 1301-1313.

Laudan R. 1987. From Mineralogy to Geology: The Fondations of a Science, 1650-1830. Chicago:

University of Chicago Press. 285 p.

Luján M., Storti F., Balanyá J-C., Crespo-Blanc A., Rossetti F. 2003. Role of décollement material with different rheological properties in the structure of Aljibe thrust imbricate (Flysch Trough, Gibraltar Arc): an analogue modelling approach. J. Struct. Geol., 25: 867-881.

Mattauer M.1973. Les déformations des matériaux de l'écorce terrestre. Paris: Hermann. 493 p.

Matthews M. R. 2012. Advances in Nature of Science Research. In M.S. Khine (ed.) Advances in Nature of Science Research, Springer, Dordrecht, p.3-26.

Merle O. 1998. Emplacements Mechanisms of Nappes and Thrust Sheets. Dordrecht: Kluwer Academica Publishers.159 p.

Morand-Aymon B. 2007. Olhares cruzados sobre a Educação Não Formal. Análise de Práticas e Recomendações. Lisboa: Direcção Geral de Formação Vocacional.

Mota T. S. 2011. A Bursting Landscape in the Middle of Portugal: Theories and Experiments by Georges Zbyszewski. Centaurus, 53:146-163.

Newcomb S. 2009. The World in a Crucible: Laboratory Practice and Geological Theory at the Beginning of Geology, Special paper 449. Boulder: Geol. Soc. Am. 204p.

Novak J. D., Gowin B. D. 1996. Aprender a Aprender. Lisboa: Plátano Edições Técnicas.

Oreskes N. 2007. From Scaling to Simulation: Changing Meanings and Ambitions of Models in Geology. In Creager A., Lunbeck E., Wise 
M. N. eds. Science without laws. Model Systems, Cases, Exemplary Narratives. Durham: Duke Univ. Press. p. 93-124.

Orion N. 2007. A Holistic Approach for Science Education For All., EJJMSTE, 3 (2): 99-106.

Ranalli G. 2001. Experimental tectonics: from Sir James Hall to the present. Journal of Geodynamics, 32:65-76.

Ribeiro A., Antunes M.T., Ferreira M.P., Rocha R.B., Soares A.F., Zbyszewski G., Moitinho de Almeida F., Carvalho, D., Monteiro J.H.1979.
Introduction à la Géologie Générale du Portugal. Lisboa: Serviços Geológicos de Portugal. 114 p. Schumm S. 1991. To interpret the Earth: Ten Ways to be Wrong. Cambridge: Univ. Press. 133 p.

Stake R. E. 2006. Multiple Case Study Analysis. New York: Guilford Press. 342 p.

Stake R. E. 2012. A arte da investigação com estudos de caso. Lisboa: Fundação Calouste Gulbenkian. $187 \mathrm{p}$.

Wilson J.T.1966. Did the Atlantic close and then reopen? Nature, 211 (5050): 676-681.

Resumo : 0 presente trabalho propõe algumas experiências de modelação análoga que simulam a formação de cadeias de montanhas no contexto dos ciclos de Wilson. Porém, não se pretende colocar apenas em evidência as fases finais do ciclo, de colisão continental, como por vezes acontece, mas também as anteriores, relacionadas ainda com a subdução, e que permitem explicar vários casos reais. A relevância desta divulgação decorre de resultados obtidos em investigações em que estas experiências foram aplicadas, em sala de aula e num Museu de Ciência. Eles revelaram que os modelos de subdução permitem que os alunos concetualizem melhor o processo real, aproximando-se dos modelos científicos mais atuais e integrando várias fases do ciclo de Wilson. Para aplicações futuras, descrevem-se os pressupostos científicos, a relação entre modelos físicos e modelos científicos e sugerem-se formas e contextos de aprendizagem para aplicação das experiências, bem como alguns cenários de enquadramento geológico atual ou passado.

Palavras-chaves: Modelação Análoga, Ciclo de Wilson, formação de montanhas, Tectónica de placas, aprendizagem formal e não-formal. 